\title{
INFLUÊNCIA DO FORNECIMENTO DE PROBIÓTICO À BASE DE Lactobacillus sp. SOBRE A MICROBIOTA INTESTINAL DE LEITÕES ${ }^{1}$
}

\author{
MAGALI SOARES DOS SANTOS ${ }^{2}$ \\ CÉLIA LÚCIA DE LUCES FORTES FERREIRA ${ }^{3}$ \\ PAULO CEZAR GOMES ${ }^{4}$ \\ JOSÉ LÚCIO DOS SANTOS 5 \\ PAULO CESAR POZZA ${ }^{6}$ \\ ELISA TESHIMA ${ }^{7}$
}

\begin{abstract}
RESUMO - Objetivou-se com este trabalho verificar o efeito do fornecimento de um "pool" de Lactobacillus sp. de origem suína para leitões nas fases de aleitamento e de creche sobre a contagem fecal de Lactobacillus, coliformes, Clostridium e Enterococcus. Foram analisadas 81 amostras fecais coletadas aos 7, 28 e 49 dias de idade, provenientes de leitões distribuídos em um delineamento experimental de blocos casualizados com três tratamentos (A- ração controle, B- ração contendo promotor de crescimento e $\mathrm{C}$ - fornecimento diário de
\end{abstract}

probiótico do $1^{\circ}$ ao $49^{\circ}$ dia de vida). O probiótico testado não foi eficiente em alterar significativamente a microbiota intestinal dos animais $(\mathrm{P}>0,10)$; entretanto, os animais que o receberam por 49 dias obtiveram, numericamente, maior contagem de Lactobacillus e menor contagem de coliformes e Clostridium em relação aos demais tratamentos, proporcionando, dessa forma, um maior desenvolvimento de microrganismos benéficos e inibindo os microrganismos patogênicos.

TERMOS PARA INDEXAÇÃO: Microbiota, leitões, probiótico.

\section{INFLUENCE OF PROBIOTIC ADMINISTRATION BASED ON Lactobacillus sp. IN INTESTINAL MICROBIOTA OF PIGLETS}

\begin{abstract}
The objective of this study was to evaluate the effect of a Lactobacillus sp. pool from swine for piglets in the suckling and nursery phases on faecal counts of Lactobacillus, coliforms, Clostridium and Enterococcus. Eighty-one faecal samples were collected at 7, 28 and 49 days of age coming from piglets arranged in a randomized block design under three treatments (A- control diet, B - diet containing a growth
\end{abstract}

INDEX TERMS: Microbiota, piglets, probiotics.

\section{INTRODUÇÃO}

Há, geralmente, dois tipos de microbiota no trato gastrointestinal. A primeira consiste na microbiota bacteriana normal, que são microrganismos benéficos que promotor, and $\mathrm{C}$, daily probiotic supply from the $1^{\text {st }}$ to $49^{\text {th }}$ day). The tested probiotic did not change efficiently the intestinal microbiota of the animals $(\mathrm{P}>0.10)$. However, probiotic treated animals to 49 days had greater Lactobacillus counts and lower coliforms and Clostridium counts than other treatments. The treated animals received greater development benefits from microorganisms, which inhibit patogenic microorganisms.

\footnotetext{
1. Parte da tese de Mestrado apresentada àUniversidade Federal de Viçosa pelo primeiro autor.

2. Ms, Professora do Curso de Zootecnia, Universidade Estadual do Oeste do Paraná UNIOESTE - Campus Marechal Cândido Rondon - Paraná.

3. Phd, Professora do Departamento de Tecnologia de Alimentos - UFV.

4. Ds, Professor do Departamento de Zootecnia - UFV.

5. Ds, Professor do Departamento de Medicina Veterinária - UFV.

6. Ds, Professor do Curso de Zootecnia UNIOESTE.

7. Ds em Ciência e Tecnologia de Alimentos.
} ro, mediante um longo período de evolução. A outra consiste em microrganismos potencialmente patogênicos, principalmente Escherichia coli (ROSELL, 1992). 
A resistência da microbiota normal à colonização do intestino por bactérias patogênicas ocorre principalmente em duas regiões do intestino: no conteúdo luminal, por causa da produção de metabólitos tóxicos, e na superfície da mucosa intestinal, em razão da ocupação dos sítios de associação pela microbiota normal (HENTGES, 1992).

Entretanto, quando se tem um ecossistema estável, não há multiplicação de microrganismos patogênicos devido à estabilização da microbiota bacteriana intestinal. Porém, nos últimos anos, com a intensificação dos sistemas de produção animal, a elevada concentração de animais oferece riscos cada vez maiores de disseminação de agentes patogênicos e instalação de processos mórbidos, visto que os sistemas de desinfecção de granjas não permitem a criação de suínos em ambientes isentos de microrganismos patogênicos.

$\mathrm{Na}$ tentativa de controlar tais problemas, o uso de antibióticos em ambos os níveis, terapêutico e subterapêutico, tem se tornado difundido. Entretanto, segundo Vassalo et al. (1997), os antibióticos e quimioterápicos tradicionalmente usados, muitas vezes, mostram-se ineficazes no controle de desordens intestinais provocadas por microrganismos patogênicos, pois verifica-se uma tendência à apresentação de casos de resistência, como conseqüência do uso freqüente de alguns princípios ativos.

Além disso, a possibilidade de que o uso de aditivos antimicrobianos na ração induza a resistência cruzada em bactérias patógenas para humanos tem levado a restrições do seu uso em muitos países. $\mathrm{O}$ aumento de infecções hospitalares causadas por bactérias resistentes a vancomicina foi associado ao uso de avoparcina como promotor de crescimento, por serem esses antibióticos estruturalmente semelhantes. Com as restrições impostas pela União Européia, os produtores europeus atualmente podem recorrer a apenas quatro promotores de crescimento e, no Brasil, os produtos que foram utilizados no passado e hoje estão proibidos como aditivos de rações incluem tetraciclinas, penicilinas, cloranfenicol, sulfonamidas sistêmicas, furazolidona, nitrofurazona e avoparcina (MENTEN, 2001).

Entre os principais promotores de crescimento alternativos aos agentes antimicrobianos estão os probióticos, que são definidos como organismos e substâncias que contribuem para o balanço microbiano no intestino (PARKER, 1974).

Segundo Jones e Thomas (1987), são sete os critérios para um microrganismo ser empregado como probiótico: i) não apresentar patogenicidade, ii) ser
Gram-positivo, iii) ser produtor de ácido e ácido resistente, iv) apresentar especificidade ao hospedeiro, v) apresentar excreção de fator anti-E. coli, vi) ser resistente à bile e vii) ser viável/estável.

Uma das vantagens dos probióticos parece ser a ausência do fenômeno de resistência, o que representa um aspecto importante em relação aos riscos da saúde pública e segurança dos produtos, uma vez que, atualmente, com o aumento da conscientização dos consumidores, esses têm exigido produtos alimentícios sem a utilização de medicamento e livre de resíduos.

Os probióticos podem ser fornecidos aos animais individualmente ou em combinações. O probiótico ideal deve ser viável e estável sob diferentes condições e propiciar desempenho zootécnico similar aos obtidos pelos antibióticos, tendo, entretanto, a vantagem de não causar dano ao homem e aos animais (FOX, 1988).

Em alguns trabalhos como os de Miles (1993) e Fox (1988), tem sido verificado que as bactérias produtoras de ácido lático são capazes de produzir substâncias antimicrobianas, como bacteriocinas e peróxido de hidrogênio; sintetizar lactato, com concomitante redução do pH intestinal; aderir à parede intestinal, prevenindo a colonização por patógenos; modificar os processos metabólicos no intestino por meio de repressão das reações que resultam em metabólitos tóxicos ou carcinogênicos e competir pelo substrato na utilização de fontes energéticas.

Assim sendo, a microbiota normal e em equilíbrio no trato gastrointestinal atua como uma barreira defensiva ao animal, impedindo a fixação de patógenos. Condições de desequilíbrio microbiano com estresse, troca de alimentação e transporte podem criar um ambiente favorável à fixação de microrganismos patogênicos.

A administração de probióticos logo após o nascimento deve-se ao fato de que, ao nascer, o trato gastrointestinal do leitão é estéril, havendo dentro de poucas horas após a exposição ao ambiente o desenvolvimento de uma abundante população microbiana. Segundo Radecki e Yokoyama (1991), E. coli e espécies de Streptococcus e Clostridium proliferam com baixo desenvolvimento de lactobacilos, pois não há secreção de ácido clorídrico nas primeiras horas de vida. Com a colonização do trato intestinal por Lactobacillus e acidificação proporcionada por esses microrganismos, há maior proteção contra a penetração de patógenos sensíveis ao meio ácido, promovendo uma rápida estabilização da microbiota normal. 
Neste trabalho, avaliou-se a influência de um "pool" de Lactobacillus sp. de origem suína administrado oralmente aos leitões nas fases de aleitamento e creche sobre a contagem fecal de Lactobacillus, Clostridium, coliformes e Enterococcus. Os Lactobacillus empregados nesta experimentação foram isolados de leitões e avaliados in vitro em trabalho anterior (PAULO, 1991).

\section{MATERIAL E MÉTODOS}

O experimento foi conduzido no Setor de Suinocultura do Departamento de Zootecnia e no Laboratório de Culturas Láticas do Departamento de Tecnologia de Alimentos, ambos da Universidade Federal de Viçosa.

Os tratamentos constituíram de: tratamento $\mathrm{A}$ (ração controle - sem promotor de crescimento), tratamento B (ração contendo antibiótico Bacitracina de Zinco) e tratamento $\mathrm{C}$ (fornecimento oral de probiótico).

O probiótico foi preparado a partir das culturas ativas obtidas do Banco de Culturas do Laboratório de Culturas Láticas da Universidade Federal de Viçosa (estirpes: P1.1 e P2.25, Lactobacillus salivarius subsp. salicinius, P3.3 L. trichodes, P4.1 L. buchneri e RP32 L. acidophilus, sendo essa última de origem suína, hoje depositada na ATCC- American Type Culture Collection sob o número 43121).

As estirpes foram incubadas individualmente a $37^{\circ} \mathrm{C}$ por 18 horas e, posteriormente, foram inoculadas na proporção de $1 \%(1 \mathrm{ml}$ de cada isolado para $100 \mathrm{ml}$ de leite desnatado reconstituído - LDR estéril) para formar o "pool" e incubadas à mesma temperatura. Após 18 horas de incubação, retirou-se a proporção de $20 \%$ do "pool" (20 $\mathrm{ml}$ de inóculo) para posterior incubação em LDR. O leite fermentado foi resfriado a $10^{\circ} \mathrm{C}$, quebrado o coágulo, envasado em recipientes estéreis e resfriado a $5^{\circ} \mathrm{C}$, sendo verificada a viabilidade do produto.

O probiótico, administrado oralmente aos leitões do $1^{\circ}$ ao $49^{\circ}$ dia de vida, continha em média $2,5 \times 10^{8}$ UFC/ml de um "pool" de Lactobacillus sp. sendo administrado no período da manhã: $2 \mathrm{ml}$ para os animais na fase de aleitamento e $5 \mathrm{ml}$ na fase de creche.

Para avaliar a administração dos diferentes promotores de crescimento, probiótico e antibiótico, em relação à influência sobre a microbiota intestinal dos animais, foram coletadas 81 amostras fecais provenientes de nove leitões por tratamento escolhidos aleatoriamente no início da fase de aleitamento de um total de 90 animais, com peso médio inicial de $1,33 \mathrm{~kg}$, distribuídos em um delineamento experimental de blocos ao acaso, com três tratamentos e dez animais (cinco de cada sexo), por unidade experimental. Aos 21 dias de idade, os animais foram transferidos para a creche, sendo utilizado o mesmo delineamento experimental; os mesmos três tratamentos e os mesmos animais anteriormente escolhidos para coleta fecal, sendo, a partir dessa fase, seis animais (três de cada sexo) por unidade experimental, totalizando 54 animais.

As amostras fecais coletadas aos 7, 28 e 49 dias de idade, por meio de massagens abdominais, foram colocadas em recipientes estéreis e imediatamente transportadas ao laboratório. Essas amostras foram preparadas e diluídas, adicionando-se $1 \mathrm{~g}$ de fezes em $99 \mathrm{ml}$ de solução-tampão fosfato $\mathrm{pH} \mathrm{7,2,}$ obtendo-se uma diluição inicial de 1:100. Após diluições sucessivas até $10^{-8}$, procedeu-se ao plaqueamento nos meios específicos.

Para avaliação da microbiota acidolática, foi utilizado o agar MRS para Lactobacillus; para coliformes, o VRB (Violet Red Bile Agar); para Clostridium, o RCM (Reinforced Clostridial Medium), e para Enterococcus, o ágar-azida esculina canamicina. As amostras foram diluídas até $10^{-8}$, plaqueadas em duplicata e incubadas a $37^{\circ} \mathrm{C}$, por 48 horas (MRS e RCM), 24 horas (VRB) e 72 horas (ágar azida esculina canamicina). As colônias foram contadas utilizando um contador de colônia "Quebec", e os resultados obtidos, expressos como log na base 10 da contagem por grama do peso das fezes.

As rações fareladas foram formuladas para atender às exigências dos suínos de acordo com Rostagno et al. (1983) e foram fornecidas à vontade aos leitões do $14^{\circ}$ ao $21^{\circ}$ dia e do $21^{\circ}$ ao $49^{\circ}$ dia de idade.

O modelo experimental usado nas análises microbiológicas foi o de parcelas subdivididas, com três tratamentos nas parcelas, dispostos no delineamento em blocos casualizados. As medições ao longo do tempo constituíram as subparcelas, sendo os dados analizados utilizando-se o programa SAEG desenvolvido pela Universidade Federal de Viçosa (UFV, 1999).

\section{RESULTADOS E DISCUSSÃO}

Em relação à viabilidade do probiótico, as contagens médias de Lactobacillus do leite fermentado em ágar MRS, a $37^{\circ} \mathrm{C}$ por 48 horas de incubação em anaerobiose, foram de $2,85 \times 10^{8}$ para o tempo 0 e de $2,47 \times 10^{8}, 2,35 \times 10^{8}$ e $2,30 \times 10^{8}$, pa- 
ra os tempos três, cinco e sete dias, respectivamente, quando mantido à temperatura de $5^{\circ} \mathrm{C}$, tendo o produto sido então preparado semanalmente e descartada qualquer sobra após uma semana.
Os resultados das contagens de Lactobacillus, Enterococcus, Clostridium e coliformes em leitões aos 7, 28 e 49 dias de idade encontram-se nas Tabelas 1, 2 e 3 , respectivamente.

TABELA 1 - Logaritmos das médias do número de unidades formadoras de colônias (UFC/g) de Lactobacillus, Enterococcus, Clostridium e coliformes, por grama de fezes, nos animais dos grupos-controle, antibiótico e probiótico, aos 7 dias de idade.

\begin{tabular}{lccc}
\hline \multirow{2}{*}{ Microrganismos } & \multicolumn{3}{c}{ Tratamentos } \\
\cline { 2 - 4 } & Controle & Antibiótico & Probiótico \\
\hline Lactobacillus & $9,47 \pm 0,48$ & $9,33 \pm 0,83$ & $9,46 \pm 0,26$ \\
Enterococcus & $7,80 \pm 1,10$ & $8,07 \pm 0,72$ & $8,20 \pm 0,96$ \\
Clostridium & $9,86 \pm 0,32$ & $9,60 \pm 0,57$ & $9,76 \pm 0,34$ \\
coliformes & $8,03 \pm 0,52$ & $7,87 \pm 0,31$ & $8,19 \pm 0,38$ \\
\hline
\end{tabular}

Não houve diferença significativa $(\mathbf{P}>0,10)$.

TABELA 2 - Logaritmos das médias do número de unidades formadoras de colônias (UFC/g) de Lactobacillus, Enterococcus, Clostridium e coliformes, por grama de fezes, nos animais dos grupos-controle, antibiótico e probiótico, aos 28 dias de idade.

\begin{tabular}{lccc}
\hline \multirow{2}{*}{ Microrganismos } & \multicolumn{3}{c}{ Tratamentos } \\
\cline { 2 - 4 } & Controle & Antibiótico & Probiótico \\
\hline Lactobacillus & $8,73 \pm 0,63$ & $9,01 \pm 0,25$ & $9,35 \pm 0,05$ \\
Enterococcus & $6,43 \pm 0,74$ & $6,68 \pm 0,20$ & $8,15 \pm 0,90$ \\
Clostridium & $9,51 \pm 0,51$ & $9,45 \pm 0,39$ & $9,54 \pm 0,16$ \\
coliformes & $8,22 \pm 1,59$ & $7,56 \pm 1,72$ & $8,55 \pm 1,11$ \\
\hline
\end{tabular}

Não houve diferença significativa $(P>0,10)$.

TABELA 3 - Logaritmos das médias do número de unidades formadoras de colônias (UFC/g) de Lactobacillus, Enterococcus, Clostridium e coliformes, por grama de fezes, nos animais dos grupos-controle, antibiótico e probiótico, aos 49 dias de idade.

\begin{tabular}{lccc}
\hline \multirow{2}{*}{ Microrganismos } & \multicolumn{3}{c}{ Tratamentos } \\
\cline { 2 - 4 } & Controle & Antibiótico & Probiótico \\
\hline Lactobacillus & $9,64 \pm 0,22$ & $9,67 \pm 0,18$ & $9,56 \pm 0,17$ \\
Enterococcus & $6,60 \pm 1,07$ & $6,18 \pm 1,05$ & $6,43 \pm 1,04$ \\
Clostridium & $9,77 \pm 0,13$ & $9,82 \pm 0,24$ & $9,77 \pm 0,11$ \\
coliformes & $7,74 \pm 1,17$ & $6,89 \pm 1,65$ & $6,58 \pm 0,83$ \\
\hline
\end{tabular}

Não houve diferença significativa $(P>0,10)$.

Ciênc. agrotec., Lavras. V.27, n.6, p.1395-1400, nov./dez., 2003 
Neste experimento, as contagens de Lactobacillus, Enterococcus, Clostridium e coliformes não foram influenciadas $(\mathrm{P}>0,10)$ pelos tratamentos, não sendo observada interação significativa entre os períodos de coleta e os tratamentos.

As contagens médias de Lactobacillus e coliformes foram de 9,42 UFC/g e 8,03 UFC/g, respectivamente, aos sete dias de idade, e de 9,03 UFC/g e 8,11 $\mathrm{UFC} / \mathrm{g}$, aos 28 dias de idade, tendo sido verificado que, após o desmame, os números de coliformes aumentaram e os de Lactobacillus diminuíram. Tais resultados são similares aos encontrados por McAllister et al. (1979), que examinaram segmentos do trato intestinal de leitões e verificaram aumento na população de $E$. coli (de 6,70 UFC/g na fase de aleitamento para 8,40 UFC/g pós-desmame) e diminuição na população de Lactobacillus (de 8,20 UFC/g para 6,5 UFC/g, respectivamente).

Embora a diferença não tenha sido significativa, o grupo de leitões que recebeu probiótico aos sete dias de idade apresentou, numericamente, menor contagem de Clostridium, quando comparado ao grupo-controle (Tabela 1). A mesma observação foi constatada ao comparar o tratamento probiótico com o antibiótico, aos 49 dias de idade (Tabela 3).

Quanto aos coliformes, aos 49 dias de idade, observou-se menor número no grupo probiótico $(6,58$ UFC/g), quando comparado ao controle (7,74 UFC/g) e ao grupo com antibiótico $(6,89 \mathrm{UFC} / \mathrm{g})$. As contagens de Lactobacillus aos 28 dias de idade foram maiores para os animais do grupo probiótico $(9,35 \mathrm{UFC} / \mathrm{g})$, quando comparadas às dos animais dos grupos controle (8,73 UFC/g) e antibiótico (9,01 UFC/g) (Tabela 2), sendo também essas diferenças somente numéricas, pois não houve diferença significativa entre os tratamentos.

Resultados semelhantes foram encontrados por Gilliland et al. (1978), que estudaram a influência do consumo de leite não-fermentado que continha células de $L$. acidophilus na microbiota fecal de humanos e verificaram, embora sem haver diferença significativa, que os números de coliformes diminuíram durante o período experimental, em relação ao grupo-controle, e que o número de Lactobacillus facultativos aumentou.

Ozawa et al. (1983) verificaram, embora sem haver diferença estatística, que a administração de probiótico em leitões desmamados promoveu estabilização da microbiota lática (Enterococcus, Lactobacillus e bactérias bífidas), sendo o provável mecanismo de ação do probiótico testado a alteração do balanço ecológico no intestino, substituindo ou eliminando microrganismos patogênicos de um modo geral.

Por sua vez, Jonsson e Conway (1992) constataram aumento nas contagens de Enterococcus com a administração de Lactobacillus acidophilus. Os autores verificaram ainda diminuição do número de coliformes e aumento da microbiota lática, como resultado do consumo de probiótico.

A administração de bactérias benéficas impede a fixação dos patógenos, ajudando a manter o equilíbrio mesmo em situações adversas. Uma possível explicação, segundo Jonsson e Conway (1992), é a capacidade de os microrganismos benéficos competirem por nutrientes e por locais de ligação no epitélio intestinal, produzindo metabólitos, como o ácido lático e ácido acético, capazes de reduzir seletivamente o número de patógenos, sendo esse mecanismo conhecido como exclusão competitiva.

São encontrados na literatura resultados contraditórios em relação ao uso de probióticos no manejo animal. Vanbelle et al. (1990), citados por Chaves (1997), listaram algumas das possíveis causas de resultados irregulares obtidos com probióticos como: tipo de microrganismo utilizado, viabilidade, condições de armazenamento, estabilidade das diferentes cepas de microrganismos durante o processamento da ração, presença de outros aditivos na ração e condições sanitárias das instalações.

\section{CONCLUSÕES}

Verificou-se que o probiótico testado não alterou significativamente a microbiota dos leitões aos 7, 28 e 49 dias de idade; entretanto, os animais que receberam diariamente o leite fermentado contendo um pool de Lactobacillus obtiveram numericamente menor contagem de Clostridium e coliformes e proporcionalmente maior número de Lactobacillus em relação aos animais dos demais tratamentos, constatando-se, provavelmente, o mecanismo de exclusão competitiva.

\section{REFERÊNCIAS BIBLIOGRÁFICAS}

CHAVES, A. H. Isolamento, identificação e teste de Lactobacillus acidophilus como probiótico para bezerro. 1997. 142 f. Dissertação (Mestrado em Zootecnia) - Universidade Federal de Viçosa, Viçosa, 1997.

FOX, S. M. Probiotics: intestinal inoculants for production animals. Veterinary Medicine, Kansas, v. 83, n. 8, p. 806-830, Aug. 1988. 
GILLILAND, S. E.; SPECK, M. L.; NAUYOK, G. F. Influence of consuming nonfermented milk containing Lactobacillus acidophilus on fecal flora of healthy males. Jounal of Dairy Science, Cambridge, v. 61, n. 1, p. 1-10, Jan. 1978.

HENTGES, D. J. Gut flora and disease resistence. In: FULLER, R. Probiotes: the scientific basis. London: Chapman e Hall, 1992. cap. 5, p. 87-109.

JONES, C. D.; THOMAS, C. N. The maintenance of strain specificity and bile tolerance when producing stable bacteria. In: LYONS, T. P. (Ed.). Biotechnology in the feed industry: procedings of Allthech's thirth annual symposium. Nicholasvile: Allthech Techinical, 1987. p. $157-166$.

JONSSON, E.; CONWAY, P. Probiotics for pigs. In: FULLER, R. (Ed.) Probiotes: the scientific basis. London: Chapman e Hall, 1992. cap. 11, p. 259-315.

MILES, R. D. Manipulation of the microflora of the gastrointestinal tract: natural ways to prevent colonization by pathogens. In: LYONS, T. P. (Ed.). Biotechnology in the feed industry: procedings of Allthech's ninth annual symposium. Nicholasvile: Allthech Techinical, 1993. p. 133-150.

MENTEN, J. F. M. Aditivos alternativos na nutrição de aves: probióticos e prebióticos. In: REUNIÃO ANUAL DA SOCIEDADE BRASILEIRA DE ZOOTECNIA, 38., 2001, Piracicaba. Resumos... Piracicaba: SBZ, 2001. p. 141-157.

McALLISTER, J. S.; KURTZ, H. J.; SHORT JÚNIOR, E. C. Changes in the intestinal flora of young pigs with postweaning diarrhea or edema disease. Journal of Animal Science, Champaing, v. 49, n. 2, p. 868-879, Feb. 1979.
OZAWA, K.; YABU-UCHI, K.; YAMANAKA K. Efect of Streptococcus faecalis BIO-4R on intestinal flora of weanling piglets and calves. Applied Environment Microbiology, Washington, v. 45, n. 5, p. 1513, May. 1983.

PAULO, E. M. Isolamento e caracterização de Lactobacillus acidophilus de fezes de suínos para uso como probiótico. 1991. 73 f. Dissertação (Mestrado em Microbiologia Agrícola) - Universidade Federal de Viçosa, Viçosa, 1991.

PARKER, R. B. Probiotics: the other half of the antibiotics story. Animal Nutrition and Health, London, v. 29, n. 2, p. 4-8, Feb. 1974.

RADECKI, S. V.; YOKOYAMA, M. T. Intestinal bacteria and their influence on swine nutrition. In: MILLER, E. R.; ULLREY, D. E.; LEWIS, A. (Eds.). Swine nutrition. [S.1.]: Butterworth-Heinemann, 1991. cap. 27 , p. 439-447.

ROSELL, V. Acidification and probiotics in spanish pig and calf rearing. In: FULLER, R. Probiotes: the scientific basis. London: Chapman e Hall, 1992. cap. 9, p. $176-180$

ROSTAGNO, H. S.; SILVA, D. J.; COSTA, P. M. A. Composição de alimentos e exigências nutricionais de aves e suínos: tabelas brasileiras. Viçosa: UFV, 1983. 61 p.

UNIVERSIDADE FEDERAL DE VIÇOSA. Manual de utilização do programa SAEG - Sistema para Análise Estatísticas e Genéticas. Viçosa: UFV, 1999. 59 p.

VASSALO, M.; FIALHO, E. T.; OLIVEIRA, A. I. G. Probióticos para leitões dos 10 aos $30 \mathrm{Kg}$ de peso vivo. Revista da Sociedade Brasileira de Zootecnia, Viçosa, v. 26, n. 1, p. 131-138, jan. 1997. 